\title{
Effect of tyrosine hydroxylase overexpression in lymphocytes on the differentiation and function of $T$ helper cells
}

\author{
HUI-WEI HUANG ${ }^{*}$, CONG ZUO* ${ }^{*}$ XIAO CHEN, YU-PING PENG and YI-HUA QIU \\ Department of Physiology, School of Medicine, Nantong University, Nantong, Jiangsu 226001, P.R. China
}

Received July 21, 2015; Accepted June 3, 2016

DOI: $10.3892 / \mathrm{ijmm} .2016 .2639$

\begin{abstract}
The aim of the present study was to examine the effect of the overexpression of tyrosine hydroxylase (TH), a rate-limiting enzyme for the synthesis of catecholamines (CAs), in lymphocytes on the differentiation and function of $\mathrm{T}$ helper (Th) cells. A recombinant $\mathrm{TH}$ overexpression plasmid (pEGFP-N1-TH) was constructed and transfected into mesenteric lymphocytes using nucleofection technology. These cells were stimulated with concanavalin A (Con A) for $48 \mathrm{~h}$ and then examined for TH expression and CA content, as well as for the percentage of Th1 and Th2 cells, cytokine concentrations and for the levels of signaling molecules. The lymphocytes overexpressing TH also expressed higher mRNA and protein levels of $\mathrm{TH}$, and synthesized more CAs, including norepinephrine (NE), epinephrine (E) and dopamine (DA) than the mock-transfected control cells. TH gene overexpression in the lymphocytes reduced the percentage of interferon- $\gamma$ (IFN- $\gamma)$-producing $\mathrm{CD} 4{ }^{+}$cells and the ratio of $\mathrm{CD} 4^{+} \mathrm{IFN}-\gamma^{+} / \mathrm{CD} 4^{+} \mathrm{IL}-4^{+}$cells, as well as the percentages of $\mathrm{CD} 4^{+} \mathrm{CD} 26^{+}$and $\mathrm{CD} 4^{+} \mathrm{CD} 30^{+}$cells and the ratio of $\mathrm{CD} 4{ }^{+} \mathrm{CD} 26^{+} / \mathrm{CD} 4^{+} \mathrm{CD} 30^{+}$cells. $\mathrm{TH}$ overexpression also reduced the secretion of IFN- $\gamma$ and tumor necrosis factor (TNF) from lymphocytes. Moreover, NE inhibited the Con A-induced lymphocyte proliferation and decreased both cyclic adenosine monophosphate (cAMP) levels and p38 mitogen-activated protein kinase (MAPK) expression in the lymphocytes. Our findings thus indicate that TH gene overexpression promotes the polarization and differentiation of $\mathrm{CD} 4{ }^{+}$cells towards Th2 cells, and this effect is mediated by the cAMP and p38 MAPK signaling pathways.
\end{abstract}

Correspondence to: Dr Yu-Ping Peng or Dr Yi-Hua Qiu, Department of Physiology, School of Medicine, Nantong University, 19 Qixiu Road, Nantong, Jiangsu 226001, P.R. China

E-mail: yppeng@ntu.edu.cn

E-mail: yhqiu@ntu.edu.cn

*Contributed equally

Key words: tyrosine hydroxylase, catecholamines, helper $\mathrm{T}$ cells, pEGFP-N1-TH, cyclic adenosine monophosphate, p38 mitogenactivated protein kinase

\section{Introduction}

It is well known that tyrosine hydroxylase (TH), a rate-limiting enzyme for the synthesis of catecholamines (CAs), is expressed in neurons and endocrine cells. Over the years, studies have demonstrated that immunocytes can synthesize and secrete CAs, including dopamine (DA), norepinephrine (NE) and epinephrine (E) (1-6). Therefore, the role of CAs is likely to be more complex than previously thought. Endogenous CAs in immunocompetent cells modulate many functions of the immune system $(7,8)$. We have also previously demonstrated that lymphocytes express $\mathrm{TH}$, and that the three types of CAs exist in lymphocytes $(9,10)$. Subsequently, we demonstrated that lymphocyte-derived endogenous CAs inhibit lymphocyte proliferation and interleukin (IL)-2 production, and accelerate lymphocyte apoptosis $(11,12)$. However, the role of endogenous CAs synthesized and secreted by lymphocytes in immunomodulation and the relevant mechanisms require further investigation.

Classically, $\mathrm{CD} 4^{+} \mathrm{T}$ cells can be functionally differentiated into T helper (Th) 1 cells and Th2 cells. Th1 cells are mainly involved in the cellular immune response through the secretion of cytokines, such as IL-2, interferon- $\gamma($ IFN- $\gamma)$ and tumor necrosis factor (TNF). Th2 cells mainly mediate the humoral immune response and exert anti-inflammatory effects through the secretion of IL-4, IL-5 and IL-10 (13). It has been reported that a high expression of CD26 (also known as dipeptidyl peptidase IV) correlates with the production of Th1-like cytokines (14), whereas Del Prete et al (15) suggested that human $\mathrm{CD} 4^{+} \mathrm{Th} 2$ cell clones express a higher amount of CD30, a member of the TNF receptor superfamily. Moreover, since there is a fine regulation of Th1- and Th2-type immune responses to maintain the normal immune balance in the body (16), a Th1/ Th2 imbalance is associated with the onset and progression of a number of autoimmune diseases, microbial infection and tumors (17-20). It has been reported that exogenous CAs can inhibit the secretion of pro-inflammatory cytokines and promote the release of anti-inflammatory cytokines (21). Although there is recent pharmacological evidence indicating that lymphocytederived CAs induce a shift in the Th1/Th2 balance toward Th2 polarization, that and $\alpha_{1}$-adrenoceptors (ARs) and $\beta_{2}$-ARs are involved in mediating this effect $(22,23)$, less is known about the role of the AR-coupled signaling pathway.

The present study was therefore undertaken to further explore the effects of lymphocyte-derived CAs on the differentiation and function of Th cells by inducing the overexpression 
of the TH gene in lymphocytes. We also aimed to elucidate the possible signaling pathway mediating these effects. These findings may provide a better understanding of the role of endogenous CAs in the neuroimmune network and may lead to advancements in the prevention and treatment of some autoimmune diseases.

\section{Materials and methods}

Cell separation and culture. The mesenteric lymph nodes of ICR mice (Center of Experimental Animals, Nantong University, Nantong, China) were harvested by celiotomy and single cell suspensions were obtained by gently squeezing the lymph nodes. The cells were then washed twice and resuspended in RPMI-1640 medium supplemented with $10 \%$ heat-inactivated calf serum, $2.5 \times 10^{-2} \mathrm{M}$ HEPES, $1 \times 10^{-3} \mathrm{M}$ sodium pyruvate, $5 \times 10^{-5} \mathrm{M}$ mercaptoethanol and antibiotics (100 U/ml penicillin, $100 \mathrm{U} / \mathrm{ml}$ streptomycin), at a final concentration of $1 \times 10^{6}$ cells $/ \mathrm{ml}$. Concanavalin A (Con A; $\left.5 \mu \mathrm{g} / \mathrm{ml}\right)$ was added to the suspensions in the presence or absence of NE to induce cell proliferation. The cultures were then incubated at $37^{\circ} \mathrm{C}$ in a moist atmosphere with $5 \% \mathrm{CO}_{2}$ for $48 \mathrm{~h}$. The animal experiments carried out in this study were in accordance with the National Institutes of Health Guide for the Care and Use of Laboratory Animals and were approved by the Institutional Animal Care and Use Committee of Nantong University.

Construction of recombinant plasmid. The pEGFP-N1 plasmid was kindly provided by the Department of Immunology of School of Medicine, Nantong University. Standard molecular biology techniques were used for the construction of the pEGFP-N1-TH recombinant plasmid. The PCR product of mouse TH fragment was restricted and inserted between the XhoI and HindIII restriction sites in the pEGFP-N1-basic vector. The forward and reverse primers used to amplify this fragment were 5'-CCCAAGCTTATGCCCACCCCCAGCG CCTC-3' and 5'-CCGCTCGAGTTAGCTAATGGCACTC AGTG-3', respectively (NM_ 009377.1). The plasmid was verified by restriction enzyme digestion by XhoI and HindIII and DNA sequencing.

Transfection with TH overexpression vector. The constructed plasmid, pEGFP-N1-TH (pEGFP-N1-TH group), or the empty vector, pEGFP-N1 (mock group), were transfected into the lymphocytes using nucleofection technology (Amaxa Biosystems, Koln, Germany) according to the manufacturer's instructions. Briefly, following incubation with Con A for $48 \mathrm{~h}$, the lymphocytes were resuspended in $100 \mu \mathrm{l}$ of $\mathrm{T}$ cell nucleofector solution. The plasmid $(4 \mu \mathrm{g})$ was added to $100 \mu 1$ of $5 \times 10^{6}$ lymphocyte suspension. The mixtures were subsequently transferred to an electroporation cuvette with aluminum electrodes and placed in the nucleofection device (Amaxa Biosystems). The nucleofection of these cells were accomplished using the X-001 program, and the samples were immediately transferred to 12 -well plates containing $2 \mathrm{ml}$ pre-warmed medium. The transfection efficiency was determined by the fluorescence-positive cells under a fluorescence microscope (Leica, Wetzlar, Germany). The number of GFP-labeled cells was approximately $50-70 \%$ (data not shown).
Reverse transcription-quantitative PCR (RT-qPCR). Total RNA was extracted from the lymph node cells which had been transfected and incubated for $48 \mathrm{~h}$, with TRIzol reagent (Invitrogen, Carlsbad, CA, USA) according to the manufacturer's instructions. This process was followed by reverse transcription into cDNA using M-MLV reverse transcriptase (Promega, Madison, WI, USA). Real-time PCR for the detection of TH was performed in a Rotor-Gene 3000 RealTime Cycler (Corbett Research, Sydney, Australia) and the detection was made by measuring the binding of the fluorescence dye SYBR-Green I (Molecular Probe, Invitrogen, Eugene, OR, USA) to double-stranded DNA. Each $20 \mu \mathrm{l}$ of reaction mixture contained $2 \mu \mathrm{l}$ of cDNA, $2 \mu \mathrm{l}$ PCR buffer, $3.0 \mathrm{mM} \mathrm{MgCl} 2,0.2 \mathrm{mM}$ of each dNTP, $0.2 \mu \mathrm{M}$ of each pair of oligonucleotide primers, and 1 unit TaqDNA polymerase. The sequences of oligonucleotide primers for the amplification of specific TH gene (130 bp, NM_009377.1) were 5'-CGGAAGC TGATTGCAGAGAT-3' (sense) and 5'-GGGTAGCATAGAG GCCCTTC-3' (antisense). The reaction procedures were as follows: an initial step at $95^{\circ} \mathrm{C}$ for $5 \mathrm{~min}, 40$ cycles of $94^{\circ} \mathrm{C}$ for $15 \mathrm{sec}, 60^{\circ} \mathrm{C}$ for $20 \mathrm{sec}$ and $72^{\circ} \mathrm{C}$ for $20 \mathrm{sec}$. Analysis was performed by the standard curve method. To verify the specificity of the amplification reaction, melting curve analysis was performed. The relative expression level of TH was expressed as a ratio relative to the value of $\beta$-actin, the housekeeping gene. The primer sequences for the $\beta$-actin gene (218bp,NM_007393) were5'-CTGTCCCTGTATGCCTCTG-3' (sense) and 5'-ATGTCACGCACGATTTCC-3' (antisense).

Western blot analysis. Total protein was extracted from the lymph node cells which were transfected with the plasmid pEGFP-N1-TH or treated with NE $\left(10^{-5} \mathrm{M}\right.$; Sigma-Aldrich, St. Louis, MO, USA) for $48 \mathrm{~h}$. The cells were homogenized in lysis buffer and the supernatants were collected by centrifugation at $4^{\circ} \mathrm{C}$ at $12,000 \mathrm{xg}$ for $15 \mathrm{~min}$. The supernatants containing $20 \mu \mathrm{g}$ of total cellular protein were mixed with loading buffer and boiled for $10 \mathrm{~min}$. The proteins were separated by $10 \%$ sodium dodecyl sulfate-polyacrylamide gel electrophoresis (SDS-PAGE) and transferred onto PVDF membranes (Pall, Port Washington, NY, USA) using a wet transfer apparatus. After blocking non-specific binding with 5\% (w/v) non-fat dry milk, the membranes were probed with mouse monoclonal antibodies specific for TH (MAB318, 1:500; Millipore Co., Billerica, MA, USA), or with rabbit monoclonal antibodies specific for p38 mitogen-activated protein kinase (MAPK; 4511P, 1:1,000) and p-CREB (9198S, 1:1,000) (both from Cell Signaling Technology Inc., Beverly, MA, USA) at $4^{\circ} \mathrm{C}$ overnight, followed by incubation with a fluorescent-conjugated affinity purified goat anti-mouse IgG (610-130-121) or goat anti-rabbit IgG (611-132122) (1:5,000; Rockland Immunochemicals Inc., Gilbertsville, PA, USA) for $1 \mathrm{~h}$ at room temperature and visualization by a Odyssey laser scanning system (LI-COR Biosciences, Lincoln, NE, USA). The blots were reprobed with monoclonal mouse anti- $\beta$-actin antibody (ab6276, 1:1,000; Sigma-Aldrich) to confirm equal protein loading. The molecular weight and relative quantity of the protein bands were determined by an image analysis system (Odyssey 3.0 software).

High performance liquid chromatography with electrochemical detection (HPLC-ED) assay of CAs. For the detection 
of CAs in the cultured lymphocytes which were transfected with the TH overexpression vector, the cultures were centrifuged and the cell pellet was resuspended in $0.15 \mathrm{ml}$ of $0.1 \mathrm{~N}$ perchloric acid and disrupted by ultrasonication. The mixture was then supplemented with $0.15 \mathrm{ml}$ of $0.8 \mathrm{~N}$ perchloric acid and centrifuged for $15 \mathrm{~min}$ at $12,000 \mathrm{x} \mathrm{g}$ at $4^{\circ} \mathrm{C}$. The supernatants were recovered, filtered and stored at $-80^{\circ} \mathrm{C}$ until analysis. For the detection of CAs in the supernatants of the lymphocyte cultures, the culture supernatants were collected after the cultures were centrifuged. To prevent electrochemical interference in the HPLC-ED by unidentified compounds, CAs in the cell supernatants were subjected to alumina-extraction. Briefly, $2 \mathrm{ml}$ of cell supernatant were added to $40 \mathrm{mg}$ of alumina, and $2 \mathrm{ml}$ of $0.5 \mathrm{M}$ Tris buffer, and gently shaken for $15 \mathrm{~min}$ at room temperature in the dark. The samples were centrifuged at $1,500 \mathrm{x} \mathrm{g}$ for $5 \mathrm{~min}$. The supernatant was discarded and the alumina was washed 3 times with cold deionized water. Finally, CAs was eluted into $0.5 \mathrm{ml}$ of $0.5 \mathrm{M}$ perchloric acid by continuously vortexing for $10 \mathrm{~min}$. Each extract of $20 \mu \mathrm{l}$ was injected into a HPLC apparatus equipped with a reverse-phase column (Altantis ${ }^{\mathrm{TM}} \mathrm{dC18}, 5 \mu \mathrm{m}, 100 \AA$ Aं Waters, Milford, MA, USA) to quantify NE, E and DA. The mobile phase was pumped at a flow rate of $1.0 \mathrm{ml} / \mathrm{min}$. NE, E and DA in the samples was quantified by using the peak areas of a standard curve.

Intracellular cytokine staining. Intracellular cytokine staining was quantified as previously described (24) with modifications. In brief, following $48 \mathrm{~h}$ of transfection with $\mathrm{TH}$ overexpression vector, the lymphocytes were stimulated with phorbol 12-myristate 13-acetate (PMA, $50 \mathrm{ng} / \mathrm{ml}$ ) and ionomycin $(1 \mu \mathrm{M})$ (both from Sigma-Aldrich) in the presence of GolgiStop (BD Pharmingen, San Diego, CA, USA) at the concentration recommended by the manufacturer for $5 \mathrm{~h}$. Following stimulation, the cells were harvested and stained with fluorescein isothiocyanate (FITC)-conjugated anti-CD4 (eBioscience, San Diego, CA, USA) and with phycoerythrin $(\mathrm{PE})$-conjugated anti-IFN- $\gamma$ or PE-labeled anti-IL-4 antibodies (all from BD Phamingen) following fixation and permeabilization. The stained cells were analyzed using a FACSCalibur flow cytometer with CellQuest software (BD Biosciences, San Jose, CA, USA).

Three-color flow cytometry. Briefly, the cells, having been transfected and incubated for $48 \mathrm{~h}$, were harvested and washed twice with ice-cold phosphate-buffered saline (PBS) containing $1 \%$ bovine serum albumin and subsequently $10^{6}$ cells/test were incubated with anti-CD4-FITC antibody for $30 \mathrm{~min}$ on ice. After washing, the cells were treated with peridinin chlorophyll protein complex with cyanin-5.5 (PerCP-Cy5.5)-conjugated anti-CD26 or PE-conjugated anti-CD30 antibodies (all antibodies were from eBioscience) for a further $30 \mathrm{~min}$ on ice. After final washing, the expression of cell surface markers was analyzed on a FACSCalibur flow cytometer.

Cytometric bead array (CBA) immunoassay. Following transfection with $\mathrm{TH}$ overexpression vector, the supernatants of the lymphocyte cultures were collected for cytokine measurements. A mouse Th1/Th2 cytokine CBA kit (BD Biosciences) was used to measure the IL-2, IFN- $\gamma$, TNF, IL-4 and IL-5 levels. The procedure was carried out according to the manufacturer's instructions. Briefly, $50 \mu \mathrm{l}$ of test samples and the provided standard cytokines were added to the premixed capture beads. After the addition of $50 \mu \mathrm{l}$ of a mixture of PE-conjugated antibodies against the cytokines, the mixture was incubated for $2 \mathrm{~h}$ in the dark at room temperature. The mixture was then washed and centrifuged at $500 \mathrm{x}$ g for $5 \mathrm{~min}$ and the pellet was resuspended in $300 \mu 1$ of wash buffer. The flow cytometer (BD Pharmingen) was calibrated with setup beads and 5,000 events were acquired for each sample. The results were analyzed using BD CBA analysis software (BD Biosciences).

Cell proliferation assay. MTT assay was used to measure cell proliferation quantitatively. The lymphocytes were incubated with $5 \mu \mathrm{g} / \mathrm{ml}$ Con A in the absence or presence of NE $\left(10^{-5}\right.$ or $\left.10^{-6} \mathrm{M}\right)$ at $37^{\circ} \mathrm{C}$ in a moist atmosphere with $5 \% \mathrm{CO}_{2}$ for $48 \mathrm{~h}$. The MTT (Sigma-Aldrich) solution of $5 \mathrm{mg} / \mathrm{ml}$ was added to the cultures (10 $\mu \mathrm{l}$ MTT solution/100 $\mu \mathrm{l}$ medium) and the cells were cultured for an additional $4 \mathrm{~h}$. Subsequently, the cells were lysed using dimethylsulfoxide (Sigma-Aldrich). When the formanzan crystals were completely dissolved, the optical density (OD) was measured at $570 \mathrm{~nm}$ using a microplate reader (Bio-Tek, Winooski, VT, USA).

Immunoassay for cAMP content. Following incubation with $\mathrm{NE}\left(10^{-5} \mathrm{M}\right)$ for $48 \mathrm{~h}$, the lymphocytes were washed with cold PBS, adjusted to a concentration of $1 \times 10^{7}$ cells $/ \mathrm{ml}$, treated with $1 \mathrm{~N} \mathrm{HCl}$ at room temperature for $10 \mathrm{~min}$ and centrifuged at $600 \mathrm{x} \mathrm{g}$ for $10 \mathrm{~min}$ at $4^{\circ} \mathrm{C}$. The supernatants were neutralized with $1 \mathrm{~N} \mathrm{NaOH}$. Cell lysate was used to measure cAMP levels using the cAMP immunoassay kit (R\&D Systems, Inc., Minneapolis, MN, USA) according to the manufacturers' instructions. Briefly, after washing with wash buffer, the streptavidin-coated microplate was incubated with biotinylated primary antibody to cAMP for $1 \mathrm{~h}$ at room temperature. After washing, cAMP conjugated to horseradish peroxidase was added to the wells immediately. The cell lysates or standards were then added to the wells and incubated for $2 \mathrm{~h}$ at room temperature. Tetramethylbenzidine with hydrogen peroxide was added to each well after washing, followed by incubation for $30 \mathrm{~min}$ at room temperature away from light. The action was terminated with stop solution. The absorbance was determined with a microplate reader (Bio-Tek) at $450 \mathrm{~nm}$. The cAMP concentrations were calculated by comparing with a curve derived from the standards provided with each kit.

Statistical analysis. Data are expressed as the means \pm standard deviation (means $\pm \mathrm{SD}$ ). Statistical analysis was performed with the Statistical Package for Social Science (SPSS 16.0). The data were subjected to one-way analysis of variance (ANOVA), followed by the Student-Newman-Keul's test to compare the data of all groups between each other. Differences were considered statistically significant at $\mathrm{p}<0.05$.

\section{Results}

Transfection of lymphocytes with TH gene overexpression plasmid increases TH expression and the CA content in these cells. The plasmid, pEGFP-N1-TH, was constructed and then transfected into lymphocytes that had been activated by Con A. The mRNA and protein expression of TH in the lymphocytes 

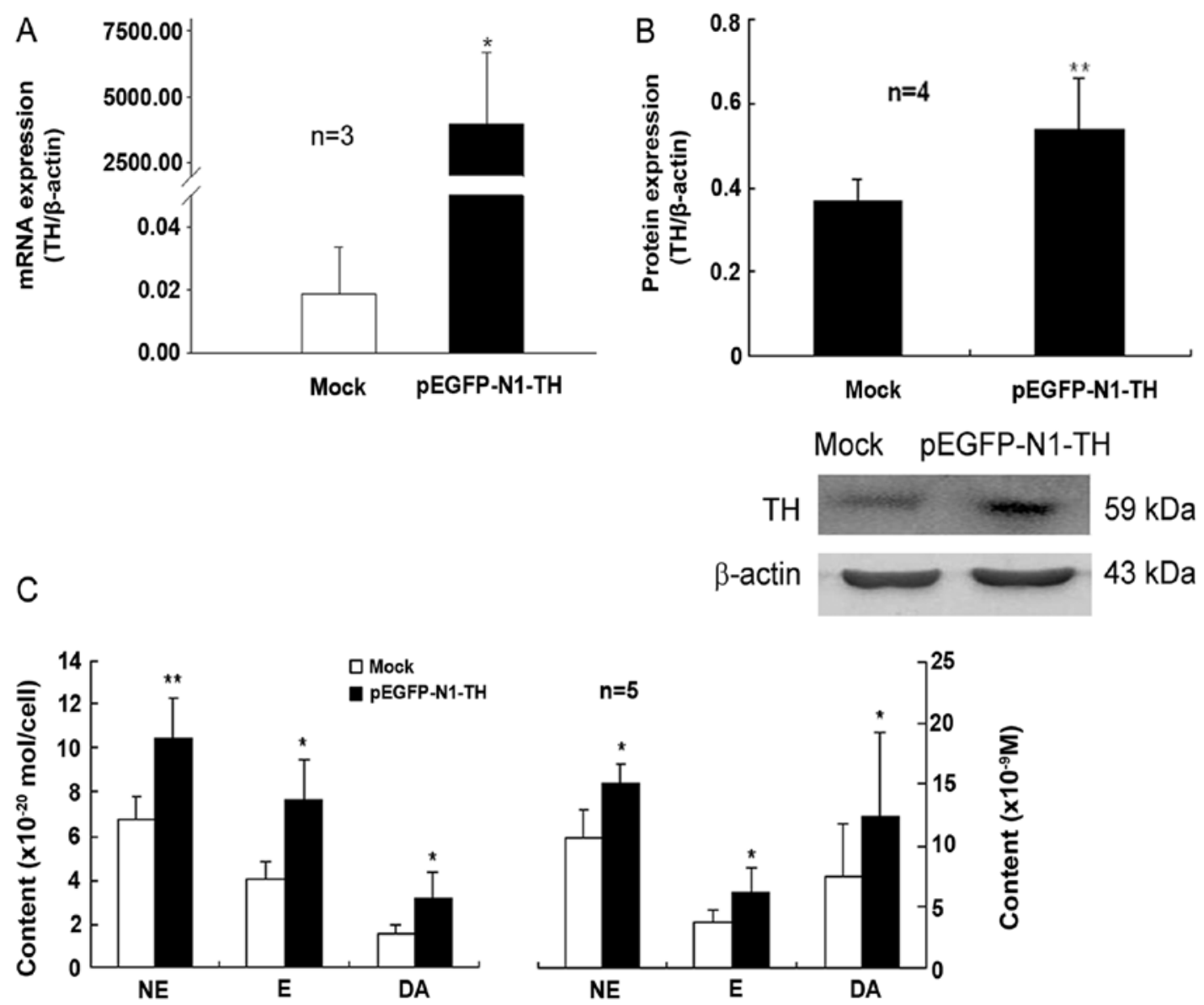

Figure 1. Effects of tyrosine hydroxylase (TH) gene overexpression on TH expression and catecholamine (CA) synthesis in lymphocytes. (A) TH mRNA expression in lymphocytes after transfection was determined by RT-qPCR. (B) TH protein expression in lymphocytes after transfection was measured by western blot analysis. (C) Contents of intracellular and supernatant CAs, including norepinephrine (NE), epinephrine (E) and dopamine (DA) in the lymphocytes were detected by HPLC-ED. The data shown are the means \pm SD from 3 or 4 or 5 repeated experiments. ${ }^{*} p<0.05$ and ${ }^{* *}$ p $<0.01$ vs. the mock-transfected control cells.

transfected with the TH overexpression plasmid was markedly upregulated compared to that of the mock-transfected control cells (Fig. 1A and B). Moreover, the contents of intracellular and supernatant CAs, including NE, E and DA in the Con A-activated lymphocytes were significantly increased by $\mathrm{TH}$ gene overexpression compared with those of the control cells (mock-transfected cells) (Fig. 1C). These data indicated that transfection with the TH gene overexpression plasmid led to an evident enhancement of TH expression and CA synthesis in the Con A-activated lymphocytes.

Effect of TH overexpression in lymphocytes on Th1/Th2 differentiation. To further confirm that CAs regulate Th1/Th2 differentiation in vitro, we examined IFN- $\gamma$-and IL-4-producing $\mathrm{CD}^{+} \mathrm{T}$ cells in Con A-activated lymphocytes transfected with $\mathrm{TH}$ overexpression vector using intracellular cytokine staining. TH gene overexpression in lymphocytes markedly decreased the percentage of IFN- $\gamma$-producing $\mathrm{CD}^{+} \mathrm{T}$ cells when compared with the mock-transfected cells, indicating that CAs suppressed Th1 cell differentiation (Fig. 2A). However, TH overexpression did not significantly alter the percentage of IL-4-producing $\mathrm{CD} 4^{+}$cells. Therefore, the ratio of $\mathrm{CD} 4^{+} \mathrm{IFN}-\gamma^{+} / \mathrm{CD} 4^{+} \mathrm{IL}-4^{+}$was notably lower in the lymphocytes transfected with the TH gene overexpression vector than in the mock-transfected control cells (Fig. 2C).
Furthermore, TH gene overexpression in the lymphocytes markedly decreased both the percentage of $\mathrm{CD} 4{ }^{+} \mathrm{CD} 26^{+} \mathrm{T}$ cells and the percentage of $\mathrm{CD} 4^{+} \mathrm{CD} 30^{+} \mathrm{T}$ cells (Fig. $2 \mathrm{~B}$ ). The ratio of $\mathrm{CD} 4{ }^{+} \mathrm{CD} 26^{+} / \mathrm{CD} 4{ }^{+} \mathrm{CD} 30^{+}$was also significantly lower in the lymphocytes transfected with the $\mathrm{TH}$ gene overexpression vector than in the mock-transfected control cells (Fig. 2C). These results indicated that an increase in the CA content promoted a shift in Th1/Th2 differentiation toward Th2.

TH gene overexpression in lymphocytes reduces Thl cytokine secretion. To determine the effects of TH overexpression in lymphocytes on Th cell function, cytokines relevant to the different Th subsets were quantified in the supernatant. Specifically, IL-2, TNF, IFN- $\gamma$, IL-4 and IL-5 were quantified. No significant differences were observed in the concentrations of IL-2, IL-4 and IL-5 (Fig. 3), whereas the concentrations of IFN- $\gamma$ and TNF were significantly decreased in the culture supernatants of lymphocytes transfected with the TH overexpression vector compared with those of the mock-transfected control cells (Fig. 3). These data indicated that TH gene overexpression in lymphocytes reduced Th1 cytokine secretion.

NE inhibits proliferation and downregulates the cAMP levels and 38 MAPK expression in lymphocytes activated by Con A. The MTT OD values of the lymphocytes treated with NE at 
A

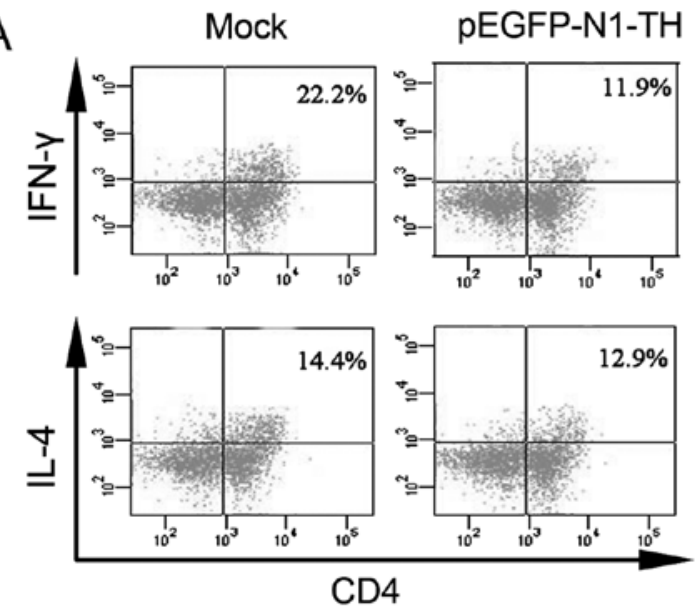

B

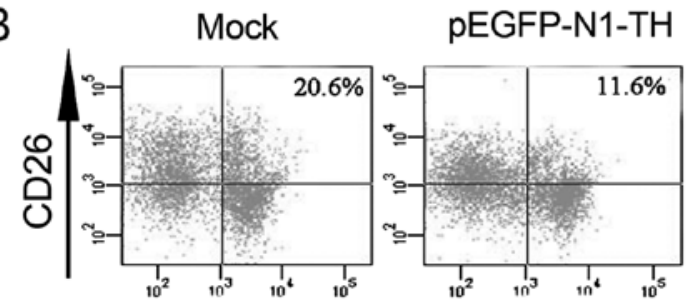

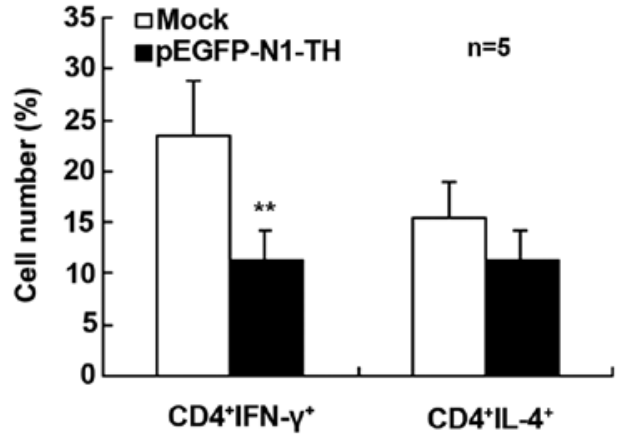

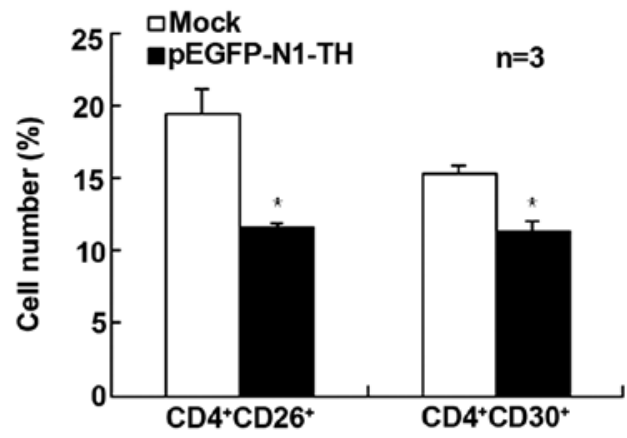

CD4
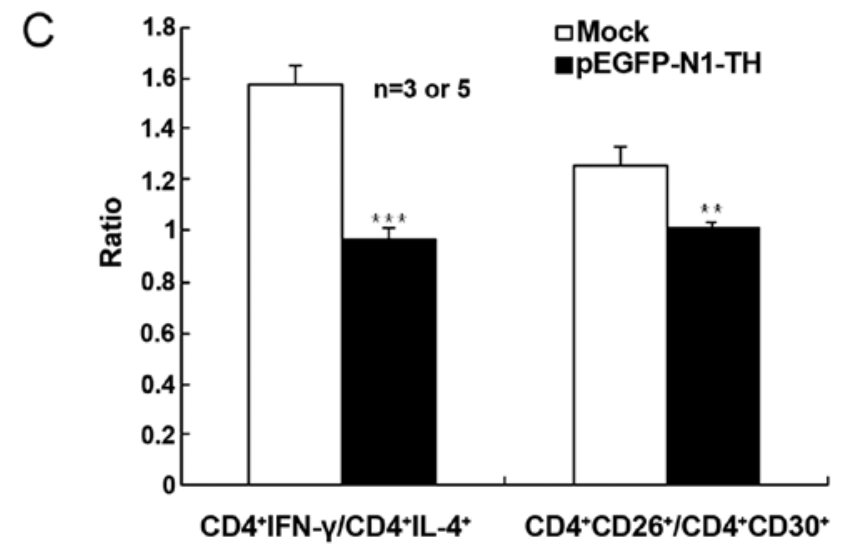

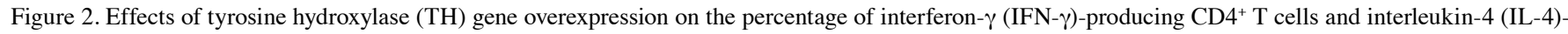
producing $\mathrm{CD}^{+} \mathrm{T}$ cells, and on the percentage of $\mathrm{CD} 4{ }^{+} \mathrm{CD} 26^{+}$cells and $\mathrm{CD} 4^{+} \mathrm{CD} 30^{+}$cells. (A) Representative FACS images and statistical graph of cytokine profiles showing the percentage of IFN- $\gamma$ - and IL-4-producing $\mathrm{CD}^{+} \mathrm{T}$ cells. The number in the upper right quadrant of each dot plot represents the percentage of Th1 cells $\left(\mathrm{CD} 4{ }^{+} \mathrm{IFN}-\gamma^{+}\right)$or Th2 cells $\left(\mathrm{CD} 4+\mathrm{IL}-4^{+}\right)$. The isotype controls were tested in preliminary experiments and did no differ from unstained samples (data not shown). Thus, unstained samples were used to set the quadrant. (B) Representative FACS image and statistical graph for 3 independent experiments is shown. The numbers indicate the percentage of $\mathrm{CD} 4{ }^{+} \mathrm{CD} 26^{+}$cells or $\mathrm{CD} 4{ }^{+} \mathrm{CD} 30^{+}$cells in the respective quadrants within viable lymphocytes. (C) Denotes the ratio in number of $\mathrm{CD} 4{ }^{+} \mathrm{IFN}-\gamma^{+} / \mathrm{CD} 4^{+} \mathrm{IL}-4^{+}$and in number of $\mathrm{CD} 4^{+} \mathrm{CD} 26^{+}$cells to $\mathrm{CD} 4^{+} \mathrm{CD} 30^{+}$cells. ${ }^{*} \mathrm{p}<0.05,{ }^{* *} \mathrm{p}<0.01$ and ${ }^{* * *} \mathrm{p}<0.001$ vs. the mock-transfected control cells.

$10^{-6}$ or $10^{-5} \mathrm{M}$ were markedly reduced when compared with those of the control cells not treated with NE (Fig. 4A). These findings indicate an attenuating effect of $\mathrm{NE}$ on Con A-induced lymphocyte proliferation.

To further determine the signal transduction pathway involved in the effects of CAs on lymphocytes, intracellular cAMP was measured by immunoassay. As shown in Fig. 4B, in the Con A-stimulated lymphocytes exposed to $\mathrm{NE}\left(10^{-5} \mathrm{M}\right)$, the content of cAMP was lower than that of the control cells.

Exposure of the Con A-stimulated lymphocytes to $\mathrm{NE}\left(10^{-5} \mathrm{M}\right)$ elicited a reduction in the expression of $\mathrm{p} 38 \mathrm{MAPK}$ compared to the control (Fig. 4C and D). However, NE did not significantly affect CREB activation (Ser133 phosphorylation, p-CREB) compared with the control (Fig. 4). 


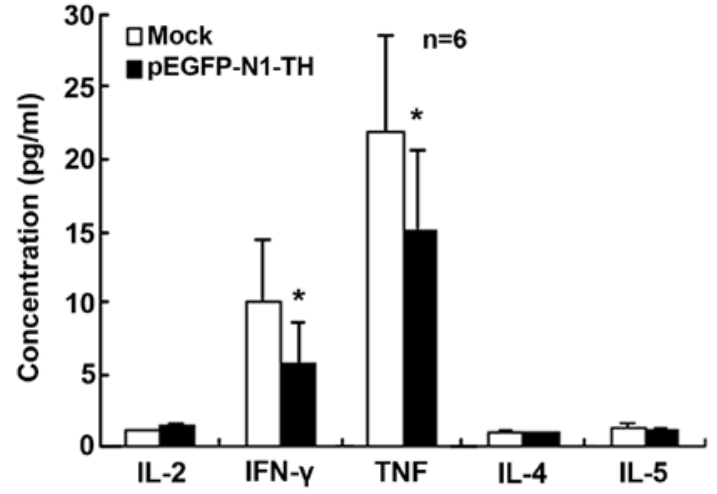

Figure 3. Effects of tyrosine hydroxylase (TH) gene overexpression on the secretion of Th1- and Th2-type cytokines by lymphocytes. Concentrations of interleukin (IL)-2, interferon- $\gamma$ (IFN- $\gamma$ ), tumor necrosis factor (TNF), IL-4 and IL-5 were assessed in the culture supernatants of lymphocytes by cytometric bead array (CBA) immunoassay. Data are shown as the means \pm SD from 6 separate experiments. ${ }^{*} \mathrm{p}<0.05$ compared with the mock-transfected control cells.

\section{Discussion}

Previous studies, including those from our laboratory, have shown that lymphocytes express TH and synthesize and secrete CAs $(1,9)$. Antigen or mitogen stimulation can increase the synthesis and secretion of CAs by lymphocytes $(9,10,25,26)$. Therefore, in the present study, Con A was used to activate lymphocytes and to increase the basal levels of CAs. We found that $\mathrm{TH}$ overexpression elevated the expression of $\mathrm{TH}$ and the synthesis of CAs in the Con A-activated lymphocytes. These results reveal that the process of CA synthesis catalyzed by $\mathrm{TH}$ also exists in lymphocytes and show the effectiveness of $\mathrm{TH}$ gene overexpression on the elevation of CA synthesis.
The overexpression of the $\mathrm{TH}$ gene in lymphocytes induced a decrease in the percentage of IFN- $\gamma$-producing $\mathrm{CD} 4^{+} \mathrm{T}$ cells and in the ratio of $\mathrm{CD} 4^{+} \mathrm{IFN}-\gamma^{+} / \mathrm{CD} 4^{+} \mathrm{IL}-4^{+}$, and in the percentages of $\mathrm{CD} 4^{+} \mathrm{CD} 26^{+}$and $\mathrm{CD} 4^{+} \mathrm{CD} 30^{+}$cells and the ratio of $\mathrm{CD}^{+}{ }^{+} \mathrm{CD} 26^{+} / \mathrm{CD} 4^{+} \mathrm{CD} 30^{+}$cells. It is well known that IFN- $\gamma$-producing and IL-4-producing $\mathrm{CD} 4^{+} \mathrm{T}$ cells represent Th1 and Th 2 cells, respectively. In IFN- $\gamma$-producing $\mathrm{CD}^{+} \mathrm{T}$ cells, CD26 expression is higher (14), whereas in $\mathrm{T}$ cells producing Th2-type cytokines, CD30 expression is increased (15). Accordingly, our present results strongly indicate that TH gene overexpression suppresses Th1 differentiation, but enhances Th2 differentiation. It has been reported that Th1 cells exert their effects via the production of cytokines, such as IL- 2 and IFN- $\gamma$, and Th2 cells implement their functions via the production of cytokines, such as IL-4 and IL-10 (13). The present study demonstrated that the concentrations of IFN- $\gamma$ and TNF in the culture supernatants of Con A-activated lymphocytes transfected with the TH gene overexpression vector were significantly lower than those of the control, although no significant differences were observed in the IL-2, IL-4 and IL-5 concentrations. The concentrations of cytokines in culture supernatants represent secreted levels by lymphocytes. Thus, the reduction of Th1-type cytokines, IFN- $\gamma$ and TNF, indicates an attenuation of Th1 function. These results reveal that $\mathrm{TH}$ gene overexpression in lymphocytes promotes a functional bias towards Th2 cells, suggesting that lymphocyte-derived CAs can promote Th cell function towards Th2 polarization. The present data extend our recent findings showing that $\alpha$-methyl-p-tyrosine ( $\alpha-\mathrm{MT})$, an inhibitor of TH, upregulates the expression of T-bet and IFN- $\gamma$, but downregulates the expression of GATA-3 and IL-4 in lymphocytes and that pargyline, an inhibitor of monoamine oxydase that degrades CAs, has the opposite effects to those of $\alpha$-MT (22), supporting
A ํㅗㄹ

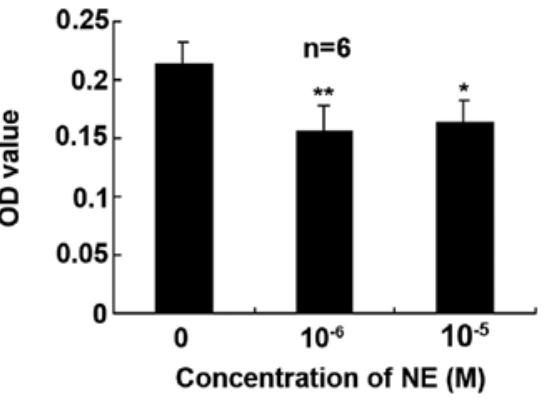

C

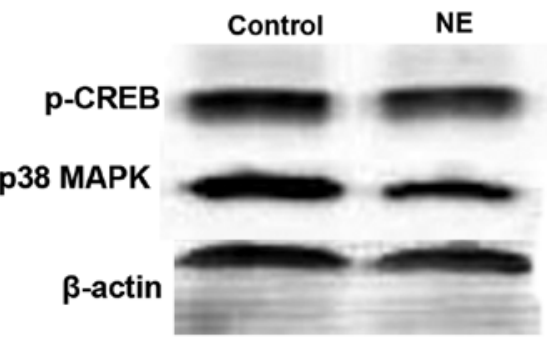

B

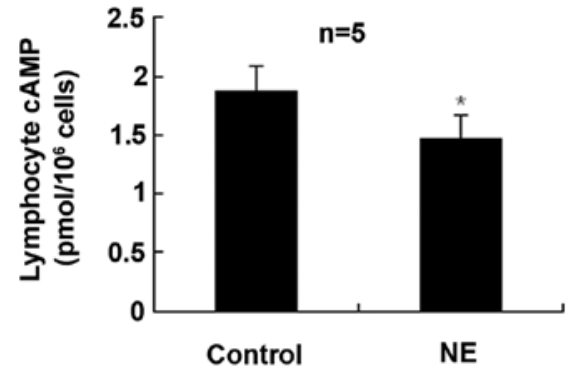

43 kDa

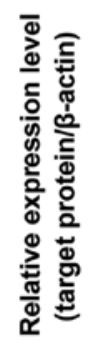

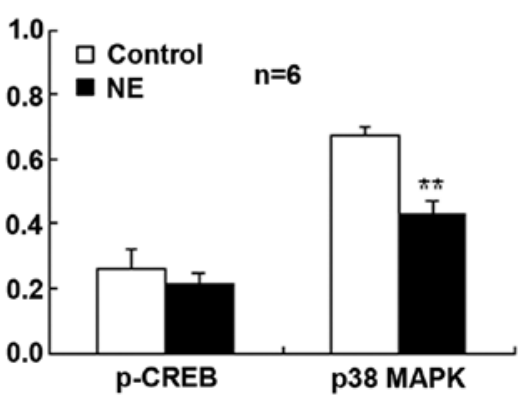

Figure 4. Effect of norepinephrine (NE) on the Con A-induced lymphocyte proliferation, as well as cyclic adenosine monophosphate (cAMP) levels and p38 MAPK expression. (A) MTT assay was used to measure the proliferative response of the lymphocytes to Con A. NE inhibited the proliferative response of the lymphocytes to Con A. ${ }^{*} \mathrm{p}<0.05$ and ${ }^{* *} \mathrm{p}<0.01$, compared with the zero point (without NE). (B) Immunoassay was employed to measure the cAMP content in lysates of cells. NE reduced the cAMP levels in lymphocytes. " $\mathrm{p}<0.05$ vs. the control not treated with NE. (C) The protein expression of p-CREB and p38 MAPK was detected by western blot analysis. NE downregulated the protein expression of p38 MAPK in the Con A-activated lymphocytes. ${ }^{* *} \mathrm{p}<0.01$ vs. the control not treated with NE. The data shown are the means \pm SD from (A and C) 6 or (B) 5 separate experiments. 
the viewpoint that lymphocyte-endogenous CAs regulate the Th1/Th2 balance and promote Th2 polarization. It has been reported that CAs derived from neurons and endocrine cells suppress the cellular immunity and shift the Th1/Th2 cytokine balance towards the Th2 profile $(21,27-29)$. These effects of exogenously added CAs are similar to the present findings of endogenous CAs from lymphocytes. Therefore, we suggest that the effects of exogenous CAs also probably represent an action of endogenous CAs, as they can be secreted out of lymphocytes into extracellular fluid to exert their modulatory effects through autocrine/paracrine pathways $(25,30,31)$. Furthermore, our present findings of the role of lymphocyte-derived CAs in the modulation of the Th1/Th2 balance extend the knowledge on neuroimmunomodulation by CAs. The immunoregulation by endogenous CAs derived from lymphocytes is probably more important than that by exogenous CAs arising from neurons or endocrine cells, as lymphocyte-derived endogenous CAs have closer and more direct contact with immune cells.

In addition, the present study demonstrated that $\mathrm{TH}$ overexpression promoted CA synthesis in Con A-activated lymphocytes, not only at the intracellular level, but also in the supernatant; among the three types of CAs, NE was the most effective. To confirm that the influence of $\mathrm{TH}$ overexpression on the function of lymphocytes may be related to NE, our studies employed NE to explore the effects and reveal the possible mechanisms. The effect that NE inhibited the proliferation of lymphocytes is similar to the present finding that TH overexpression attenuated the differentiation and function of Th1 cells. Recently, we demonstrated that the CA effect of promoting Th2 polarization was mediated by $\alpha_{1}$-AR and $\beta_{2}-A R$, but not by $\alpha_{2}$-AR or $\beta_{1}$-AR by using respective AR antagonists (23), suggesting that both $\alpha_{1}-\mathrm{AR}$ and $\beta_{2}-\mathrm{AR}$ are involved in the role of CAs. Canonically, the stimulation of $\alpha_{1}$-AR activates the PLC-PKC signaling pathway and the stimulation of $\beta_{2}$-AR activates the cAMP-PKA signaling pathway. In addition, it has been reported that NE stimulation of the $\beta A R / G s / P K A$ pathway activates p38 MAPK and leads to changes in T cell dynamics (32), suggesting that p38 MAPK is involved in $\beta$-AR signaling. Dissimilarly, the present results show that NE simulation of lymphocytes decreases cAMP/p38 MAPK signaling. This inconsistency may be explained by a mutual regulation between $\alpha_{1}$-AR and $\beta_{2}$-AR. It has been presented that PKC and PKA may cause the phosphorylation of $\beta_{2}-A R$, which results in the receptor desensitization and represents a negative feedback loop (33-36). For example, the stimulation of $\alpha_{1}$-AR causes the phosphorylation of $\beta_{2}$-AR in the human prostate, most likely by $\mathrm{G}$ protein-coupled receptor kinase 2 , which may result in the desensitization of $\beta_{2}-A R$ and the enhancement of $\alpha_{1}$-AR (37). On the other hand, the phosphorylation of $\beta$-AR decreases its affinity for Gs, whereas it increases Gi binding $(38,39)$. Therefore, the reduced cAMP/p38 MAPK signaling in lymphocytes by $\mathrm{NE}$ in this study suggests a possibility of negative regulation of $\beta_{2}$-AR signaling by $\alpha_{1}$-AR activation.

The Th1/Th2 balance is crucial to maintain the functional homeostasis of the immune system. Once the balance is broken, it leads to the onset and progression of autoimmune diseases. A number of autoimmune diseases, such as rheumatoid arthritis (RA), experimental autoimmune encephalomyelitis (EAE), autoimmune thyroiditis and systemic lupus erythematosus, have been confirmed to be associated with a Th1/Th2 imbalance. In most states of these diseases, the balance is skewed towards Th1 cells and an excess production of pro-inflammatory cytokines, whereas the production of anti-inflammatory cytokines is deficient (40-43). Studies have proven that polarizing autoimmune Th1 cells toward Th2 directions $(44,45)$ leads to the suppression of the clinical and pathological manifestations of EAE. Accordingly, the shifts of Th1/Th2 balance towards Th2 polarization by lymphocytederived CAs presented in this study imply the possible way, through which CAs alleviate autoimmune diseases. Moreover, the present results, together with those of our recent study (23), imply that the cAMP/p38 MAPK signaling pathway may be implicated in mediating Th cell differentiation and function. Therefore, the signal transduction mechanisms of CAs related to Th differentiation and function provides a basis for the therapeutic strategy of autoimmune diseases.

In conclusion, $\mathrm{TH}$ gene overexpression in lymphocytes by transfection results in an upregulation of $\mathrm{TH}$ expression and an elevation of CA synthesis. Simultaneously, TH gene overexpression facilitates a shift in Th cell differentiation and function towards Th2 cell polarization. These findings further confirm that lymphocyte-derived CAs regulate the differentiation and function of Th cells, promoting a shift in the Th1/Th2 balance towards Th2 predominance. Furthermore, NE inhibited Con A-induced lymphocyte proliferation and decreased both the cAMP level and p38 MAPK expression in lymphocytes. Accordingly, we hypothesize that the cAMP/ p38 MAPK signaling pathway may be implicated in mediating the differentiation and function of Th cells induced by the lymphocyte-derived CAs.

\section{Acknowledgements}

This study was supported by grant nos. 81271323 and 31371182 from the National Natural Science Foundation of China, no.09B14 from the Natural Science Foundation of Nantong University, KYZZ-0355 from the Postgraduate Science-Technology Innovation Program of Jiangsu Educational Committee, and a project funded by the Priority Academic Program Development (PAPD) of Jiangsu Higher Education Institutions.

\section{References}

1. Bergquist J, Tarkowski A, Ekman R and Ewing A: Discovery of endogenous catecholamines in lymphocytes and evidence for catecholamine regulation of lymphocyte function via an autocrine loop. Proc Natl Acad Sci USA 91: 12912-12916, 1994.

2. Josefsson E, Bergquist J, Ekman R and Tarkowski A: Catecholamines are synthesized by mouse lymphocytes and regulate function of these cells by induction of apoptosis. Immunology 88: 140-146, 1996.

3. Musso NR, Brenci S, Setti M, Indiveri F and Lotti G: Catecholamine content and in vitro catecholamine synthesis in peripheral human lymphocytes. J Clin Endocrinol Metab 81: 3553-3557, 1996.

4. Marino F, Cosentino M, Bombelli R, Ferrari M, Lecchini S and Frigo G: Endogenous catecholamine synthesis, metabolism storage, and uptake in human peripheral blood mononuclear cells. Exp Hematol 27: 489-495, 1999.

5. Cosentino M, Marino F, Bombelli R, Ferrari M, Lecchini S and Frigo G: Endogenous catecholamine synthesis, metabolism, storage and uptake in human neutrophils. Life Sci 64: 975-981, 1999.

6. Cosentino M, Bombelli R, Ferrari M, Marino F, Rasini E, Maestroni GJ, Conti A, Boveri M, Lecchini S and Frigo G: HPLC-ED measurement of endogenous catecholamines in human immune cells and hematopoietic cell lines. Life Sci 68: 283-295, 2000. 
7. Cosentino M, Fietta AM, Ferrari M, Rasini E, Bombelli R, Carcano E, Saporiti F, Meloni F, Marino F and Lecchini S: Human $\mathrm{CD}^{+} \mathrm{CD} 25^{+}$regulatory $\mathrm{T}$ cells selectively express tyrosine hydroxylase and contain endogenous catecholamines subserving an autocrine/paracrine inhibitory functional loop. Blood 109: 632-642, 2007.

8. Cosentino M, Marino F and Lecchini S: Resistance of naturally occurring regulatory $\mathrm{T}$ cells toward oxidative stress: Possible link with intracellular catecholamine content and implications for cancer therapy. Blood 114: 487-489, 2009.

9. Qiu YH, Peng YP, Jiang JM and Wang JJ: Expression of tyrosine hydroxylase in lymphocytes and effect of endogenous catecholamines on lymphocyte function. Neuroimmunomodulation 11: $75-83,2004$

10. Qiu YH, Cheng C, Dai L and Peng YP: Effect of endogenous catecholamines in lymphocytes on lymphocyte function. J Neuroimmunol 167: 45-52, 2005.

11. Peng YP, Qiu YH, Jiang JL and Wang JJ: Effect of catecholamines on IL-2 production and NK cytotoxicity of rats in vitro. Acta Pharmacol Sin 25: 1354-1360, 2004.

12. Jiang JL, Peng YP, Qiu YH and Wang JJ: Effect of endogenous catecholamines on apoptosis of Con A-activated lymphocytes of rats. J Neuroimmunol 192: 79-88, 2007.

13. D'Ambrosio D, Iellem A, Colantonio L, Clissi B, Pardi R and Sinigaglia F: Localization of Th-cell subsets in inflammation: Differential thresholds for extravasation of Th1 and Th2 cells. Immunol Today 21: 183-186, 2000.

14. Willheim M, Ebner C, Baier K, Kern W, Schrattbauer K, Thien R, Kraft D, Breiteneder H, Reinisch W and Scheiner O: Cell surface characterization of $\mathrm{T}$ lymphocytes and allergen-specific $\mathrm{T}$ cell clones: Correlation of CD26 expression with $\mathrm{T}(\mathrm{H} 1)$ subsets. J Allergy Clin Immunol 100: 348-355, 1997.

15. Del Prete G, De Carli M, Almerigogna F,Daniel CK,D'Elios MM, Zancuoghi G, Vinante F, Pizzolo G and Romagnani S: Preferentia expression of $\mathrm{CD} 30$ by human $\mathrm{CD}^{+} \mathrm{T}$ cells producing $\mathrm{Th} 2$-type cytokines. FASEB J 9: 81-86, 1995.

16. Kidd P: Th1/Th2 balance: The hypothesis, its limitations, and implications for health and disease. Altern Med Rev 8: 223-246, 2003.

17. Simon AK, Seipelt E and Sieper J: Divergent T-cell cytokine patterns in inflammatory arthritis. Proc Natl Acad Sci USA 91: 8562-8566, 1994.

18. Dolff S, Bijl M, Huitema MG, Limburg PC, Kallenberg CG and Abdulahad WH: Disturbed Th1, Th2, Th17 and T(reg) balance in patients with systemic lupus erythematosus. Clin Immunol 141: 197-204, 2011

19. Borgogni E, Sarchielli E, Sottili M, Santarlasci V, Cosmi L, Gelmini S, Lombardi A, Cantini G, Perigli G, Luconi M, et al: Elocalcitol inhibits inflammatory responses in human thyroid cells and T cells. Endocrinology 149: 3626-3634, 2008

20. Bleotu C, Chifiriuc MC, Grigore R, Grancea C, Popescu CR, Anton $\mathrm{G}$ and Cernescu C: Investigation of Th1/Th2 cytokine profiles in patients with laryngo-pharyngeal, HPV-positive cancers. Eur Arch Otorhinolaryngol 270: 711-718, 2013.

21. Salicrú AN, Sams CF and Marshall GD: Cooperative effects of corticosteroids and catecholamines upon immune deviation of the type-1/type- 2 cytokine balance in favor of type- 2 expression in human peripheral blood mononuclear cells. Brain Behav Immun 21: 913-920, 2007.

22. Huang HW, Tang JL, Han XH, Peng YP and Qiu YH: Lymphocytederived catecholamines induce a shift of Th1/Th2 balance toward Th2 polarization. Neuroimmunomodulation 20: 1-8, 2013.

23. Huang HW, Fang XX, Wang XQ, Peng YP and Qiu YH: Regulation of differentiation and function of helper T cells by lymphocyte-derived catecholamines via $\alpha_{1}$-and $\beta_{2}$-adrenoceptors. Neuroimmunomodulation 22: 138-151,2015.

24. Switzer KC, Fan YY, Wang N, McMurray DN and Chapkin RS Dietary n-3 polyunsaturated fatty acids promote activationinduced cell death in Th1-polarized murine $\mathrm{CD} 4{ }^{+} \mathrm{T}$-cells. J Lipid Res 45: 1482-1492, 2004.

25. Cosentino M, Marino F, Bombelli R, Ferrari M, Rasini E, Lecchini S and Frigo G: Stimulation with phytohaemagglutinin induces the synthesis of catecholamines in human peripheral blood mononuclear cells: Role of protein kinase $\mathrm{C}$ and contribution of intracellular calcium. J Neuroimmunol 125: 125-133, 2002.

26. Cosentino M, Zaffaroni M, Marino F, Bombelli R, Ferrari M, Rasini E, Lecchini S, Ghezzi A and Frigo G: Catecholamine production and tyrosine hydroxylase expression in peripheral blood mononuclear cells from multiple sclerosis patients: Effect of cell stimulation and possible relevance for activation-induced apoptosis. J Neuroimmunol 133: 233-240, 2002.
27. Elenkov IJ, Papanicolaou DA, Wilder RL and Chrousos GP Modulatory effects of glucocorticoids and catecholamines on human interleukin-12 and interleukin-10 production: Clinical implications. Proc Assoc Am Physicians 108: 374-381, 1996.

28. Takayanagi Y, Osawa S, Ikuma M, Takagaki K, Zhang J, Hamaya Y, Yamada T, Sugimoto M, Furuta T, Miyajima $H$ and Sugimoto K: Norepinephrine suppresses IFN- $\gamma$ and TNF- $\alpha$ production by murine intestinal intraepithelial lymphocytes via the $\beta_{1}$ adrenoceptor. J Neuroimmunol 245: 66-74, 2012

29. Loza MJ, Peters SP, Foster S, Khan IU and Penn RB: beta-Agonist enhances type $2 \mathrm{~T}$-cell survival and accumulation. J Allergy Clin Immunol 119: 235-244, 2007.

30. Musso NR, Brenci S, Indiveri F and Lotti G: Acetylcholineinduced, calcium-dependent norepinephrine outflow from peripheral human lymphocytes. J Neuroimmunol 87: 82-87, 1998

31. Engler KL, Rudd ML, Ryan JJ, Stewart JK and Fischer-Stenger K: Autocrine actions of macrophage-derived catecholamines on interleukin-1 $\beta$. J Neuroimmunol 160: 87-91, 2005.

32. Lajevic MD, Suleiman S, Cohen RL and Chambers DA Activation of p38 mitogen-activated protein kinase by norepinephrine in T-lineage cells. Immunology 132: 197-208, 2011.

33. Oostendorp J, Obels PP, Terpstra AR, Nelemans SA and Zaagsma J: Modulation of beta2- and beta3-adrenoceptormediated relaxation of rat oesophagus smooth muscle by protein kinase C. Eur J Pharmacol 495: 75-81, 2004.

34. Boterman M, Smits SR, Meurs H and Zaagsma J: Protein kinase $\mathrm{C}$ potentiates homologous desensitization of the beta2-adrenoceptor in bovine tracheal smooth muscle. Eur J Pharmacol 529: 151-156, 2006.

35. Tran TM, Friedman J, Qunaibi E, Baameur F, Moore RH and Clark RB: Characterization of agonist stimulation of cAMP-dependent protein kinase and G protein-coupled receptor kinase phosphorylation of the beta2-adrenergic receptor using phosphoserine-specific antibodies. Mol Pharmacol 65: 196-206, 2004.

36. Violin JD, DiPilato LM, Yildirim N, Elston TC, Zhang J and Lefkowitz RJ: beta2-adrenergic receptor signaling and desensitization elucidated by quantitative modeling of real-time cAMP dynamics. J Biol Chem 283: 2949-2961, 2008.

37. Hennenberg M,StrittmatterF, WaltherS, HedlundP,Andersson KE Stief CG, Schlenker B and Gratzke C: $\alpha_{1}$-adrenoceptor activation induces phosphorylation of $\beta_{2}$-adrenoceptors in human prostate tissue. BJU Int 108: 922-928, 2011.

38. Daaka Y, Luttrell LM and Lefkowitz RJ: Switching of the coupling of the beta2-adrenergic receptor to different $\mathrm{G}$ proteins by protein kinase A. Nature 390: 88-91, 1997.

39. Zamah AM, Delahunty M, Luttrell LM and Lefkowitz RJ: Protein kinase A-mediated phosphorylation of the beta 2-adrenergic receptor regulates its coupling to Gs and Gi. Demonstration in a reconstituted system. J Biol Chem 277: 31249-31256, 2002.

40. Horwitz DA, Gray JD, Behrendsen SC, Kubin M, Rengaraju M, Ohtsuka K and Trinchieri G: Decreased production of interleukin-12 and other Th1-type cytokines in patients with recent-onset systemic lupus erythematosus. Arthritis Rheum 41: 838-844, 1998 .

41. Nakashima H, Akahoshi M and Masutani K: Th1/Th2 balance of SLE patients with lupus nephritis. Rinsho Byori 54: 706-713, 2006.

42. Ruschpler P and Stiehl P: Shift in Th1 (IL-2 and IFN-gamma) and Th2 (IL-10 and IL-4) cytokine mRNA balance within two new histological main-types of rheumatoid-arthritis (RA). Cell Mol Biol (Noisy-le-grand) 48: 285-293, 2002.

43. Fuse K, Kodama M, Ito M, Okura Y, Kato K, Hanawa H, Aoki S and Aizawa Y: Polarity of helper T cell subsets represents disease nature and clinical course of experimental autoimmune myocarditis in rats. Clin Exp Immunol 134: 403-408, 2003.

44. Garren H, Ruiz PJ, Watkins TA, Fontoura P, Nguyen LT, Estline ER, Hirschberg DL and Steinman L: Combination of gene delivery and DNA vaccination to protect from and reverse Th1 autoimmune disease via deviation to the Th2 pathway. Immunity 15: 15-22, 2001.

45. Miyamoto K, Miyake S and Yamamura T: A synthetic glycolipid prevents autoimmune encephalomyelitis by inducing TH2 bias of natural killer T cells. Nature 413: 531-534, 2001. 